\title{
Linkage and association study of discoidin domain receptor 1 as a novel susceptibility gene for childhood IgA nephropathy
}

\author{
WON-HO HAHN, JIN-SOON SUH, BYOUNG-SOO CHO and SUNG-DO KIM \\ Department of Pediatrics, East West Kidney Diseases Research Institute, School of Medicine, \\ Kyung Hee University, Hoegi-dong \#1, Dongdaemun-gu, Seoul 130-701, Korea
}

Received December 10, 2009; Accepted February 2, 2010

DOI: 10.3892/ijmm_00000405

\begin{abstract}
In several experimental studies, it has been suggested that discoidin domain receptor 1 (DDR1) plays an important role in the regulation of mesangial proliferation, glomerular basement membrane thickening, renal fibrosis, and in the development of inflammation in several tissue types, including renal tissues. The present study was conducted to investigate the association between single nucleotide polymorphisms (SNPs) of the DDRl gene and childhood IgA nephropathy (IgAN). The genotyping data of 180 childhood IgAN patients and 336 controls showed significant differences in the frequency of rs1264319 (dominant model, $\mathrm{P}=0.040$ ). Subgroup analysis revealed that development of proteinuria (>4 and $\leq 4 \mathrm{mg} / \mathrm{m}^{2} / \mathrm{h} ; \mathrm{n}=131$ and 49 ) was significantly associated with rs2267641 (codominant model, $\mathrm{P}=0.004$; dominant, $\mathrm{P}=0.024$; recessive, $\mathrm{P}=0.010$ ) and $\mathrm{rs} 9468844$ (codominant model, $\mathrm{P}=0.003$; dominant, $\mathrm{P}=0.017$; recessive, $\mathrm{P}=0.012$ ). Furthermore, rs 1264319 frequencies were significantly different in those with pathologically mild and advanced disease subgroups ( $\mathrm{n}=162$ and 18; codominant and dominant model, $\mathrm{P}=0.022$ ). Our results suggest that $D D R 1$ gene is associated with increased susceptibility, pathological advancement, and the development of proteinuria in childhood IgAN.
\end{abstract}

\section{Introduction}

Various types of collagen are known to modulate mesangial cell proliferation, and extracellular matrix (ECM) remodeling is known to be a key event in progression and reversal of kidney diseases. Discoidin domain receptors 1 and 2 (DDRl and 2) are

Correspondence to: Dr Sung-Do Kim, Department of Pediatrics, East West Kidney Diseases Research Institute, School of Medicine, Kyung Hee University, Hoegi-dong \#1, Dongdaemun-gu, Seoul 130-701, Korea

E-mail: kimsungdo@khu.ac.kr

Abbreviations: DDR1, Discoidin domain receptor 1 gene; GN, glomerulonephritis; IgAN, IgA nephropathy; LD, linkage disequilibrium; SNP, single nucleotide polymorphism

Key words: discoidin domain receptor 1, polymorphism, IgA nephropathy, childhood receptor tyrosine kinases, and are distinguished by the discoidin module in their extracellular domain. This is a homology region that was originally identified in the protein discoidin I from Dictyostelium discoideum (1-4), and uniquely both DDRI and $D D R 2$ ligate collagens. The $D D R 1$ has been found to be activated by all collagens tested to date, including those of the basement membrane, such as type IV collagen, whereas DDR2 is only activated by fibrillar collagens (3-5). Messenger RNA (mRNA) expression of DDRl is predominantly observed in epithelial cells, particularly those from the kidney, lung, gastrointestinal tract, and brain. However, little is known about the precise cellular distribution of $D D R 1$ protein $(1,3,5-10)$. After binding collagen, $D D R 1$ is dimerized, and phosphorylated as tyrosine kinase, which leads to P38MAP/kinase activation, which means that it is the only collagen receptor known to display direct intracellular signaling activity. In addition, in vitro studies suggest that $D D R l$ is a major mediator of the inflammatory response, because it is essential for the maturation and differentiation of monocytes to macrophages (4).

Several studies have examined in vitro and in vivo effects of DDRI (5). A study of DDR1-null mouse mesangial cells, concluded that DDRI might be involved in the proliferative stage of renal disorders (1). Furthermore, the localization of DDR1 protein in rat kidney was consistent with a role in cellmatrix interactions, and also suggested its involvement in kidney injury (11). In addition, in a study on DDR1-deficient mice, it was suggested that $D D R l$ plays an important role in maintaining the structural integrity of the glomerular basement membrane (3), and in another in vivo study in DDR1-null mice, $D D R 1$ was found to participate in proteinuria, glomerular fibrosis, and renal inflammation $(2,4)$. Recently, DDR1 was suggested as a powerful regulator of collagen deposition in ECM and elucidated their multifaceted role in ECM remodeling (12).

IgA nephropathy (IgAN) is the most commonly occurring form of chronic glomerulonephritis $(\mathrm{GN})$ in pediatric patients, and the extent and intensity of glomerular injury in response to mesangial IgA deposition are extremely variable, and the extent of this response determines levels of subsequent mesangial cell proliferation and interstitial fibrosis, which lead to the development and progression of IgAN.

DDR 1 seems to be related with glomerular basement membrane integrity, podocyte slit diaphragm maintenance, mesangial proliferation and adhesion, and renal fibrosis. These relations eminently demonstrate the importance attached to the DDRl gene with respect to the pathogeneses of nephro- 
pathies. However, few studies have been conducted on polymorphisms of DDR1 in IgAN, especially in children. Thus, the present study was conducted to investigate associations between polymorphisms of the DDRl gene and childhood IgAN.

\section{Materials and methods}

Patients and controls. We examined a total of 180 Korean pediatric patients with biopsy proven IgAN [11.82 \pm 4.87 years (mean age $\pm \mathrm{SD}$ ); 102 boys, $11.84 \pm 4.87$ years; 78 girls, $11.81 \pm 4.90$ years] and 336 healthy controls $(36.40 \pm 8.32$ years; 151 males, $36.40 \pm 12.04$ years; 185 females, $37.63 \pm 8.13$ years). Patients were detected by school screening urinalysis and most of them showed no symptom of GN other than abnormalities in urinalysis. Accordingly, they were supposed to have relatively early stage disease. At our center, we perform a renal biopsy in all patients with i) unexplained prolonged isolated hematuria or proteinuria of a duration $\geq 12$ months, ii) concomitant hematuria and proteinuria for $>3$ months, iii) a second episode of gross hematuria with decreased serum $\mathrm{C} 3$ and $\mathrm{C} 4$ levels, or iv) decreased renal function. Among the $180 \mathrm{IgAN}$ patients, 3 patients had family history of chronic GN, membranous GN, IgAN, and lupus nephritis, respectively. The healthy controls were also recruited based on routine screening findings. This screening included the completion of a questionnaire, which addressed the presence of symptoms and medical history, in addition to blood pressure, electrocardiography, abdominal sonography, and laboratory test findings, such as, complete blood count, fasting glucose level, total cholesterol, triglyceride, HDL-cholesterol, rheumatoid factor, hepatitis viral markers, hemoglobin A1C, liver enzymes, blood urea nitrogen, creatinine, electrolytes, and urinalysis findings (protein, glucose, and occult blood). Control candidates with an abnormal result for any item were excluded. This study was approved by the ethics review committee of the Medical Research Institute, Kyung Hee University Medical Center, Seoul. Written informed consent was obtained from all subjects and parents or legal guardians.

Patient subgroups. To determine the nature of the association between SNPs of DDRI SNPs and the development of proteinuria, we divided patients into subgroups according to the presence of the largest amount of proteinuria during the course of IgAN being analyzed (proteinuria $>4$ and $\leq 4 \mathrm{mg} / \mathrm{m}^{2} / \mathrm{h}$, $\mathrm{n}=131$ and 49 , respectively).

IgAN patients were also subgrouped into mild and advanced disease groups to evaluate the contribution made by $D D R 1$ SNPs to disease progression and pathologic findings ( $n=162$ and 18, respectively). Members of the advanced disease group had at least one of the following, interstitial fibrosis, tubular atrophy, or global sclerosis by kidney biopsy as pathological markers.

The demographic characteristics of subgroups of IgAN patients are demonstrated in Table I. Small differences in subgroup numbers were caused by the loss of some clinical data.

Clinical characteristics of patients. We investigated amounts of proteinuria, presence of gross hematuria as a first symptom, and follow-up period from the onset of hematuria or proteinuria on the school screening to the date of kidney biopsy. Moreover, we used modified activity and chronicity indices of lupus nephritis to evaluate pathological findings objectively and semi-quantitatively. The grading criteria used to classify histologic activity were: (i) mesangial proliferation ( 0 , none; 1, mild focal; 2, mild diffuse; 3 , moderate to severe diffuse); (ii) cellular crescents $(0$, none; $1,1-10 \%$ of all glomeruli; 2 , $11-20 \%$; 3, 21-30\%; 4, 31-40\%; 5, $\geq 40 \%$ ); (iii) interstitial mononuclear cell (MNC) infiltration (0, none; 1 , focal; 2 , multifocal; 3, diffuse); and (iv) electron-dense deposits by EM (0, none; 1, a few; 2, occasional; 3, frequent; 4, heavy). The grading criteria used to classify chronicity included (i) global glomerular sclerosis (0, none; 1, 1-20\% of all glomeruli; $2,21-40 \% ; 3,41-60 \% ; 4,61-80 \% ; 5, \geq 80 \%$ ); (ii) segmental glomerular sclerosis (0, none; $1,1-20 \%$ of all glomeruli; 2 , $21-40 \% ; 3,41-60 \% ; 4,61-80 \% ; 5, \geq 80 \%$ ); (iii) tubular atrophy ( 0 , none; 1 , focal; 2 , multifocal; 3 , diffuse); and (iv) interstitial fibrosis ( 0 , none; 1 , focal; 2 , multifocal; 3 , diffuse).

SNP selection and genotyping. A total of 11 SNPs of the DDRI gene were selected based on the findings of extensive database searches (http://www.ebi.ac.uk/ensemble/, http://ncbi. nlm.nih.gov/SNP), based on heterozygosity $>0.1$ and a minor allele frequency (MAF) of $>0.05$. Eleven SNPs in DDR 1 were selected; one in its promoter (rs9461638), one in its 5untranslated region (UTR) (rs1264326), 5 in its synonymous region (rs2229933, rs1049622, rs1264319, rs1049623, rs2267641), 2 in its 3-UTR (rs1049628, and rs8408), and 2 in its 3 -near gene (rs9468843, and rs9468844). The 11 candidate SNPs are illustrated in Fig. 1.

DNA was isolated from peripheral blood sample using Core One Blood Genomic DNA Isolation Kits (CoreBioSystem, Seoul). SNP genotyping was conducted by direct sequencing. Genomic DNA was amplified using specific primers for the $11 D D R 1$ gene SNPs. Only the primers of SNPs that were shown to have significant association are listed here, rs1264326 (sense, 5'-GGTGCTGATAGTATCCACAGCTGTA-3'; antisense, 5'- TCTTGAGAGAGACTACATGGTAGGG-3'; 470 bp), rs2267641 (sense, 5'-GATGCCACCAAGAATGC CAGGTG -3'; antisense, 5'- TCACACATTCCTTATCCCA GGCC -3'; 623 bp), and rs9468843 (sense, 5'-TGGACATCTC TAGTGTAGCTGCC-3'; antisense, 5'-AGGAGGACTCAGT AGACCTCTAC-3'; 503 bp). The samples were sequenced using an ABI Prism 377 automatic sequencer (PE Applied Biosystems, Foster City, CA), and sequence data were analyzed using SeqManII software (DNAStar Inc., Madison, WI).

Statistical analysis. The significant subgroup differences with respect to clinical characteristics were determined using the Student t-test for continuous variables and the Mann-Whitney $\mathrm{U}$ test for activity and chronicity indices using SPSS, version 15.0 (Chicago, IL). P-values of $<0.05$ were regarded as statistically significant.

We analyzed 11 DDRl SNPs, rs9461638, rs1264326, rs2229933, rs1049622, rs1264319, rs1049623, rs2267641, rs1049628, rs8408, rs9468843, and rs9468844, in the 180 patients and in 336 controls. Compliance with the HardyWeinberg equilibrium (HWE), for all SNPs, was assessed using SNPstats software in both of patients and controls, relations found were adjusted for gender only. But, comparisons 
Table I. Analysis of demographic findings in IgA nephropathy patients.

\begin{tabular}{|c|c|c|c|c|c|c|}
\hline \multirow[t]{2}{*}{ Subgroups } & \multicolumn{2}{|c|}{ Proteinuria $\left(\mathrm{mg} / \mathrm{m}^{2} / \mathrm{h}\right)$} & \multirow[t]{2}{*}{ P-value } & \multicolumn{2}{|c|}{ Advanced disease markers } & \multirow[t]{2}{*}{ P-value } \\
\hline & $>4$ & $\leq 4$ & & $(+)$ & $(-)$ & \\
\hline $\mathrm{n}(\%)$ & $131(72.6)$ & $49(27.4)$ & & $18(10.0)$ & $162(90.0)$ & \\
\hline $\mathrm{M}: \mathrm{F}$ & $85: 46$ & $17: 32$ & & $15: 3$ & $87: 75$ & \\
\hline Mean age \pm SD (years) & $11.82 \pm 4.88$ & $11.91 \pm 4.92$ & & $11.93 \pm 4.96$ & $11.82 \pm 4.88$ & \\
\hline Gross hematuria $[\mathrm{n}(\%)]$ & $23(17.6)$ & $5(10.2)$ & & $4(22.2)$ & $24(14.8)$ & \\
\hline Proteinuria $\left(\mathrm{mg} / \mathrm{m}^{2} / \mathrm{h}\right)$ & $35.76 \pm 56.01$ & $2.05 \pm 1.03$ & $<0.001$ & $55.24 \pm 59.94$ & $23.34 \pm 47.93$ & 0.046 \\
\hline Follow-up period (months) & $18.18 \pm 26.56$ & $24.22 \pm 22.78$ & 0.938 & $46.99 \pm 43.44$ & $16.80 \pm 20.97$ & $<0.001$ \\
\hline Activity index & $2.96 \pm 1.82$ & $2.02 \pm 1.60$ & $0.002^{\mathrm{a}}$ & $4.17 \pm 1.79$ & $2.54 \pm 1.74$ & $0.001^{\mathrm{a}}$ \\
\hline Chronicity index & $0.23 \pm 0.80$ & $0.04 \pm 0.29$ & $0.031^{\mathrm{a}}$ & $1.78 \pm 1.48$ & $0.00 \pm 0.00$ & $<0.001^{\mathrm{a}}$ \\
\hline
\end{tabular}

aMann-Whitney U test performed comparing mean activity and chronicity indices between patient subgroups. Other continuous variables were compared using Student t-test.

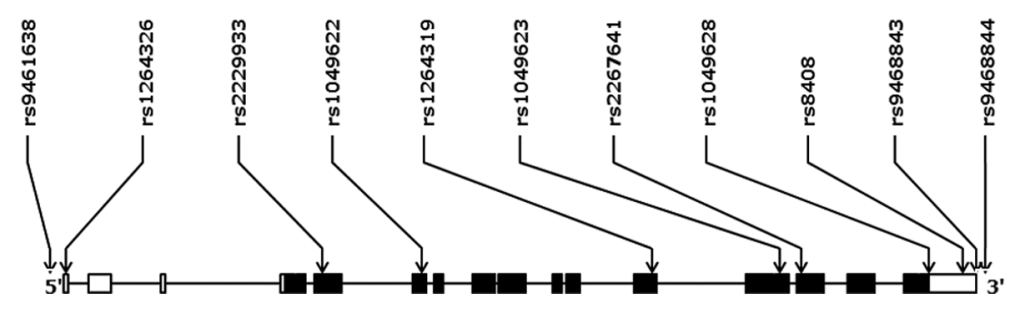

Figure 1. Gene mapping of single nucleotide polymorphisms (SNPs) of the DDR1 gene.

between $\operatorname{Ig}$ AN subgroups were adjusted for gender and age. Linkage disequilibrium (LD) block of polymorphisms was tested using Haploview (version 4.1). We used SNPstats, HapAnalyzer version 1.0 and SNPanalyzer (ISTech Inc., Goyang, Korea) to calculate odds ratios, 95\% confidence intervals (CIs), and P-values and permutation testing was also performed (13).

\section{Results}

Clinical characteristics of study subjects. As shown in Table I, certain variables were analyzed (e.g., amount of proteinuria, follow-up period, activity index, and chronicity index) in each patient subgroup. The proteinuria $>4 \mathrm{mg} / \mathrm{m}^{2} / \mathrm{h}$ group showed proteinuria levels of mean $35.76 \pm 56.01 \mathrm{mg} / \mathrm{m}^{2} / \mathrm{h}$ (vs. $2.05 \pm 1.03 \mathrm{mg} / \mathrm{m}^{2} / \mathrm{h}$ ) and showed higher activity and chronicity indices $(\mathrm{P}=0.002$ and 0.031 , respectively). The patients with markers of advanced disease had significantly more proteinuria $\left(55.24 \pm 59.94\right.$ vs. $\left.23.34 \pm 47.93 \mathrm{mg} / \mathrm{m}^{2} / \mathrm{h}, \mathrm{P}=0.046\right)$ and a longer follow-up period $(46.99 \pm 43.44$ vs. $16.80 \pm 20.97$ months) from detection by school screening tests to the time of kidney biopsy $(\mathrm{P}<0.001)$. In addition, activity index was also higher in the advanced disease group.

Genotype and allele frequencies of the target gene. The genotypic distributions of all SNPs in this study were consistent with the Hardy-Weinberg equilibrium $(\mathrm{P}>0.05)$. Genotyping data of the 180 patients and the 336 controls showed a significant association between rs1264319 (dominant model,
$\mathrm{P}=0.040)$ and the presence of $\operatorname{Ig} \mathrm{AN}$ by logistic regression analysis after adjusting for gender (Table II).

When we assessed genetic association between the 11 SNPs and the presence of proteinuria of $>4 \mathrm{mg} / \mathrm{m}^{2} / \mathrm{h}, \mathrm{rs} 2267641$ (codominant model, $\mathrm{P}=0.004$; dominant model, $\mathrm{P}=0.024$; recessive model, $\mathrm{P}=0.010$ ) and $\mathrm{rs} 9468843$ (codominat model, $\mathrm{P}=0.003$; dominant model, $\mathrm{P}=0.071$; recessive model, $\mathrm{P}=0.012$ ) showed statistically significant allele frequency differences (Table III).

Furthermore, we found a significant genetic association between pathologic advancement of $\operatorname{IgAN}$ and rs1264319 (codominant and dominant model, $\mathrm{P}=0.022$ ), this same SNP was found to be a susceptibility marker for IgAN (data not shown).

Haplotype analysis. As shown in Fig. 2, in the measurement of pair-wise linkage disequilibrium (LD), one LD block was identified by the Gabriel method (14), but no LD block showed statistically significant overall haplotype associations with IgAN using Haploview (data not shown). In the haplotype analysis, the SNP of rs1264326 was excluded, because of its low minor allele frequency in the Korean population.

\section{Discussion}

During this analysis of the clinical data of IgAN patients, several notable findings were obtained. First, the proteinuria was found to be associated with the chronicity index (e.g., presence of advancement markers). Also, the advanced disease 
Table II. Logistic regression analysis of $D D R 1$ polymorphisms in control and IgAN patients with adjustment for gender.a

\begin{tabular}{|c|c|c|c|c|c|c|}
\hline SNP & Genotype & $\begin{array}{c}\operatorname{IgAN} \\
\mathrm{n}=180(\%)\end{array}$ & $\begin{array}{c}\text { Control } \\
\mathrm{n}=336(\%)\end{array}$ & Models & OR $(95 \% \mathrm{CI})$ & P-value \\
\hline rs9461638 & $\mathrm{C} / \mathrm{C}$ & $58(32.2)$ & $87(27.8)$ & Codominant & $1.16(0.90-1.50)$ & 0.260 \\
\hline \multirow[t]{2}{*}{ Promoter } & $\mathrm{C} / \mathrm{G}$ & $85(47.2)$ & $149(47.6)$ & Dominant & $1.22(0.82-1.82)$ & 0.340 \\
\hline & $\mathrm{G} / \mathrm{G}$ & 37 (20.6) & $77(24.6)$ & Recessive & $1.23(0.78-1.92)$ & 0.370 \\
\hline rs1264326 & $\mathrm{G} / \mathrm{G}$ & $179(99.4)$ & $334(99.4)$ & Codominant & $1.28 \quad(0.19-8.66)$ & 0.790 \\
\hline \multirow[t]{2}{*}{ 5-UTR } & $\mathrm{T} / \mathrm{G}$ & $1(0.6)$ & $1(0.3)$ & Dominant & $0.99(0.09-11.20)$ & 1.000 \\
\hline & $\mathrm{T} / \mathrm{T}$ & $0(0)$ & $1 \quad(0.3)$ & Recessive & NA $\quad(0.00-\mathrm{NA})$ & 0.400 \\
\hline rs2229933 & $\mathrm{C} / \mathrm{C}$ & $58(32.4)$ & $87(26.7)$ & Codominant & $1.16(0.90-1.51)$ & 0.250 \\
\hline \multirow[t]{2}{*}{ Leu94Leu } & $\mathrm{C} / \mathrm{G}$ & $84(46.9)$ & $163 \quad(50)$ & Dominant & $1.30 \quad(0.87-1.94)$ & 0.210 \\
\hline & $\mathrm{G} / \mathrm{G}$ & $37(20.7)$ & $76(23.3)$ & Recessive & $1.14(0.73-1.78)$ & 0.560 \\
\hline rs1049622 & $\mathrm{T} / \mathrm{T}$ & $58(32.6)$ & $89(27.3)$ & Codominant & $1.16(0.89-1.50)$ & 0.270 \\
\hline \multirow[t]{2}{*}{ Ser175Ser } & $\mathrm{T} / \mathrm{C}$ & $83(46.6)$ & $160(49.1)$ & Dominant & $1.27(0.85-1.89)$ & 0.240 \\
\hline & $\mathrm{C} / \mathrm{C}$ & $37(20.8)$ & $77(23.6)$ & Recessive & $1.15(0.73-1.79)$ & 0.540 \\
\hline rs1264319 & $\mathrm{G} / \mathrm{G}$ & $158(88.3)$ & $273(81.5)$ & Codominant & $1.33(0.84-2.12)$ & 0.220 \\
\hline \multirow[t]{2}{*}{ Ser496Ser } & $\mathrm{A} / \mathrm{G}$ & $16(8.9)$ & $61(18.2)$ & Dominant & $1.72(1.01-2.95)$ & 0.040 \\
\hline & $\mathrm{A} / \mathrm{A}$ & $5 \quad(2.8)$ & $1(0.3)$ & Recessive & $0.13(0.01-1.13)$ & 0.029 \\
\hline rs1049623 & $\mathrm{G} / \mathrm{G}$ & $74(41.1)$ & $127(38.6)$ & Codominant & $1.06(0.81-1.37)$ & 0.690 \\
\hline \multirow[t]{2}{*}{ Val599Val } & $\mathrm{A} / \mathrm{G}$ & 79 (43.9) & $149(45.3)$ & Dominant & $1.09(0.75-1.58)$ & 0.660 \\
\hline & $\mathrm{A} / \mathrm{A}$ & $27 \quad(15)$ & $53(16.1)$ & Recessive & $1.05(0.63-1.74)$ & 0.850 \\
\hline rs2267641 & $\mathrm{A} / \mathrm{A}$ & $72(40.2)$ & $150(46.3)$ & Codominant & $0.85(0.65-1.12)$ & 0.250 \\
\hline \multirow[t]{2}{*}{ Pro645Pro } & $\mathrm{A} / \mathrm{C}$ & $82(45.8)$ & $135(41.7)$ & Dominant & $0.79 \quad(0.54-1.15)$ & 0.210 \\
\hline & $\mathrm{C} / \mathrm{C}$ & $25 \quad(14)$ & $39 \quad(12)$ & Recessive & $0.86 \quad(0.50-1.49)$ & 0.600 \\
\hline rs1049628 & $\mathrm{T} / \mathrm{T}$ & $57(31.7)$ & $88(26.9)$ & Codominant & $1.16(0.89-1.50)$ & 0.270 \\
\hline \multirow[t]{2}{*}{ 3-UTR } & $\mathrm{T} / \mathrm{C}$ & $86(47.8)$ & $161(49.2)$ & Dominant & $1.24 \quad(0.83-1.85)$ & 0.300 \\
\hline & $\mathrm{C} / \mathrm{C}$ & $37(20.6)$ & $78(23.9)$ & Recessive & $1.19(0.76-1.86)$ & 0.440 \\
\hline rs8408 & $\mathrm{C} / \mathrm{C}$ & $57(31.8)$ & $88(27.2)$ & Codominant & $1.15(0.89-1.49)$ & 0.290 \\
\hline \multirow[t]{2}{*}{ 3-UTR } & $\mathrm{T} / \mathrm{C}$ & $85(47.5)$ & $159(49.1)$ & Dominant & $1.24 \quad(0.83-1.85)$ & 0.300 \\
\hline & $\mathrm{T} / \mathrm{T}$ & $37(20.7)$ & $77(23.8)$ & Recessive & $1.17(0.75-1.83)$ & 0.490 \\
\hline rs9468843 & $\mathrm{T} / \mathrm{T}$ & $72(40.5)$ & $151(46.6)$ & Codominant & $0.84 \quad(0.64-1.10)$ & 0.200 \\
\hline \multirow[t]{2}{*}{ 3-near } & $\mathrm{T} / \mathrm{C}$ & $81(45.5)$ & $136 \quad(42)$ & Dominant & $0.79(0.54-1.14)$ & 0.210 \\
\hline & $\mathrm{C} / \mathrm{C}$ & $25 \quad(14)$ & $37(11.4)$ & Recessive & $0.81 \quad(0.47-1.39)$ & 0.440 \\
\hline rs9468844 & $\mathrm{C} / \mathrm{C}$ & $57(31.7)$ & $88(26.5)$ & Codominant & $1.15(0.89-1.49)$ & 0.280 \\
\hline \multirow[t]{2}{*}{ 3-near } & $\mathrm{C} / \mathrm{G}$ & $86(47.8)$ & $167(50.3)$ & Dominant & $1.27(0.85-1.89)$ & 0.250 \\
\hline & $\mathrm{G} / \mathrm{G}$ & $37(20.6)$ & $77(23.2)$ & Recessive & $1.14(0.73-1.78)$ & 0.560 \\
\hline
\end{tabular}

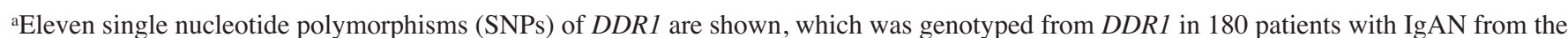
Kyung Hee Medical Center, Seoul, Korea and 336 control subjects. Total number of each SNP is different, because genotypes of some SNPs are unreadable.

Figure 2. Haplotype block organization of the $D D R I$ gene. Each box represents linkage disequilibrium (LD) (range 0-1) between pairs of single-nucleotide polymorphism (SNP) markers as generated by Haploview. Black shading indicates strong LD (no number entry means a score 1). Gray shading indicates 'uninformative', and white indicates strong evidence of recombination.

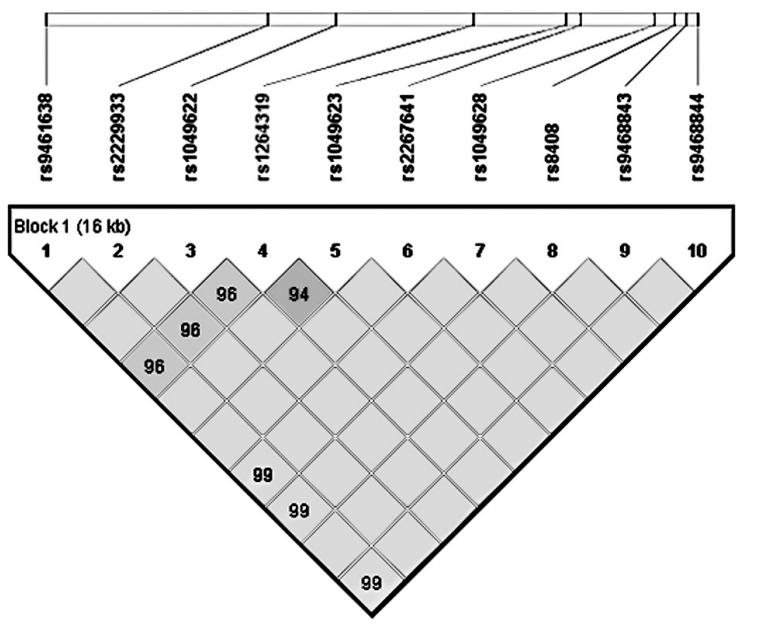


Table III. Logistic regression analysis of $D D R 1$ polymorphisms in $\operatorname{IgA}$ nephropathy patients with proteinuria $\left(>4 \mathrm{or} \leq 4 \mathrm{mg} / \mathrm{m}^{2} / \mathrm{h}\right)$ after adjustment for gender and age. ${ }^{\mathrm{a}}$

\begin{tabular}{|c|c|c|c|c|c|c|}
\hline SNP & Genotype & $\begin{array}{c}>4 \mathrm{mg} / \mathrm{m}^{2} / \mathrm{h} \\
\mathrm{n}=131(\%)\end{array}$ & $\begin{array}{c}\leq 4 \mathrm{mg} / \mathrm{m}^{2} / \mathrm{h} \\
\mathrm{n}=49(\%)\end{array}$ & Models & OR $(95 \% \mathrm{CI})$ & P-value \\
\hline rs9461638 & $\mathrm{C} / \mathrm{C}$ & $45(34.6)$ & $13(26.5)$ & Codominant & $1.13(0.70-1.82)$ & 0.620 \\
\hline \multirow[t]{2}{*}{ Promoter } & $\mathrm{C} / \mathrm{G}$ & $58(44.6)$ & $26(53.1)$ & Dominant & $1.40(0.65-2.98)$ & 0.380 \\
\hline & $\mathrm{G} / \mathrm{G}$ & $27(20.8)$ & $10(20.4)$ & Recessive & $0.96(0.41-2.24)$ & 0.920 \\
\hline rs2229933 & $\mathrm{C} / \mathrm{C}$ & $45(34.6)$ & $13(27.1)$ & Codominant & $1.13(0.70-1.82)$ & 0.620 \\
\hline \multirow[t]{2}{*}{ Leu94Leu } & $\mathrm{C} / \mathrm{G}$ & $58(44.6)$ & $25(52.1)$ & Dominant & $1.36(0.64-2.91)$ & 0.420 \\
\hline & $\mathrm{G} / \mathrm{G}$ & $27(20.8)$ & $10(20.8)$ & Recessive & $0.98(0.42-2.30)$ & 0.960 \\
\hline rs1049622 & $\mathrm{T} / \mathrm{T}$ & $45(34.6)$ & $13(27.7)$ & Codominant & $1.13(0.70-1.82)$ & 0.630 \\
\hline \multirow[t]{2}{*}{ Ser175Ser } & $\mathrm{T} / \mathrm{C}$ & $58(44.6)$ & $24(51.1)$ & Dominant & $1.33(0.62-2.84)$ & 0.460 \\
\hline & $\mathrm{C} / \mathrm{C}$ & $27(20.8)$ & $10(21.3)$ & Recessive & $1.01(0.43-2.36)$ & 0.990 \\
\hline rs1264319 & $\mathrm{G} / \mathrm{G}$ & $112(86.2)$ & $45(93.8)$ & Codominant & $0.45(0.13-1.49)$ & 0.140 \\
\hline \multirow[t]{2}{*}{ Ser496Ser } & $\mathrm{A} / \mathrm{G}$ & $13 \quad(10)$ & $3(6.2)$ & Dominant & $0.45(0.12-1.65)$ & 0.200 \\
\hline & $\mathrm{A} / \mathrm{A}$ & $5 \quad(3.8)$ & $0 \quad(0)$ & Recessive & $0.00(0.00-\mathrm{NA})$ & 0.180 \\
\hline rs1049623 & $\mathrm{G} / \mathrm{G}$ & $60(46.1)$ & $14(28.6)$ & Codominant & $1.39(0.86-2.26)$ & 0.180 \\
\hline \multirow[t]{2}{*}{ Val599Val } & $\mathrm{A} / \mathrm{G}$ & $51(39.2)$ & $27(55.1)$ & Dominant & $1.98(0.95-4.13)$ & 0.063 \\
\hline & $\mathrm{A} / \mathrm{A}$ & $19(14.6)$ & $8(16.3)$ & Recessive & $1.06(0.41-2.71)$ & 0.910 \\
\hline rs2267641 & $\mathrm{A} / \mathrm{A}$ & $46(35.7)$ & $26(53.1)$ & Codominant & $0.46(0.26-0.80)$ & 0.004 \\
\hline \multirow[t]{2}{*}{ Pro645Pro } & $\mathrm{A} / \mathrm{C}$ & $60(46.5)$ & $21(42.9)$ & Dominant & $0.45(0.22-0.91)$ & 0.024 \\
\hline & $\mathrm{C} / \mathrm{C}$ & $23(17.8)$ & $2(4.1)$ & Recessive & $0.19(0.04-0.86)$ & 0.010 \\
\hline rs1049628 & $\mathrm{T} / \mathrm{T}$ & $45(34.6)$ & $12(24.5)$ & Codominant & $1.19(0.73-1.92)$ & 0.480 \\
\hline \multirow[t]{2}{*}{ 3-UTR } & $\mathrm{T} / \mathrm{C}$ & $58(44.6)$ & $27(55.1)$ & Dominant & $1.59(0.73-3.43)$ & 0.230 \\
\hline & $\mathrm{C} / \mathrm{C}$ & $27(20.8)$ & $10(20.4)$ & Recessive & $0.96(0.41-2.24)$ & 0.920 \\
\hline rs8408 & $\mathrm{C} / \mathrm{C}$ & $45(34.9)$ & $12(24.5)$ & Codominant & $1.19(0.74-1.92)$ & 0.480 \\
\hline \multirow[t]{2}{*}{ 3-UTR } & $\mathrm{T} / \mathrm{C}$ & $57(44.2)$ & $27(55.1)$ & Dominant & $1.60(0.74-3.46)$ & 0.220 \\
\hline & $\mathrm{T} / \mathrm{T}$ & $27(20.9)$ & $10(20.4)$ & Recessive & $0.95(0.41-2.22)$ & 0.900 \\
\hline rs9468843 & $\mathrm{T} / \mathrm{T}$ & $46(35.7)$ & $26(54.2)$ & Codominant & $0.44(0.25-0.78)$ & 0.003 \\
\hline \multirow[t]{2}{*}{ 3-near } & $\mathrm{T} / \mathrm{C}$ & $60(46.5)$ & $20(41.7)$ & Dominant & $0.42(0.21-0.86)$ & 0.017 \\
\hline & $\mathrm{C} / \mathrm{C}$ & $23(17.8)$ & $2(4.2)$ & Recessive & $0.19(0.04-0.88)$ & 0.012 \\
\hline rs9468844 & $\mathrm{C} / \mathrm{C}$ & $45(34.6)$ & $12(24.5)$ & Codominant & $1.19(0.73-1.92)$ & 0.480 \\
\hline \multirow[t]{2}{*}{ 3-near } & $\mathrm{C} / \mathrm{G}$ & $58(44.6)$ & $27(55.1)$ & Dominant & $1.59(0.73-3.43)$ & 0.230 \\
\hline & $\mathrm{G} / \mathrm{G}$ & $27(20.8)$ & $10(20.4)$ & Recessive & $0.96(0.41-2.24)$ & 0.920 \\
\hline
\end{tabular}

aTen single nucleotide polymorphisms (SNPs) of DDRl were genotyped in 180 IgAN patients. Total numbers of SNP differ, because genotypes of some SNPs were not determined. rs1264326 was excluded from the analysis because of its low minor allele frequencies.

markers were found to be accompanied with higher levels of proteinuria, which means that the presence and amount of proteinuria may be related to renal disease progression. Second, the activity index was significantly higher in both of proteinuria and advanced disease groups. Third, the followup period of IgAN patients was significantly longer in the advanced disease group. This finding suggests the effort for detection of IgAN at an early stage should be made to prevent progression of disease. To detect and treat chronic kidney diseases in asymptomatic children, school urinalysis screening was instituted in 1998 for children aged 6 to 18 in Korea (15-17).

The role of $D D R 1$ in the progression of renal failure has been examined in DDR1-null mice in the angiotensin II (Ang II)-induced model of renal disease. Wild-type mice developed hypertension, perivascular inflammation, glomerular sclerosis, and severe proteinuria, but in DDR1-deficient mice, proteinuria, glomerular fibrosis, and renal inflammation were significantly blunted $(2,4)$. Immunostaining for lymphocytes, macrophages, and the abnormal accumulations of collagens I and IV were prominent in the renal cortex of wild-type animals, but negligible in DDR1-null mice. Interestingly, DDR1-null mice showed blunted chemokine response to lipopolysaccharide and an enhanced survival against lipopolysaccharide-induced mortality. Thus, it was concluded that DDRI might participate in fibrosis by amplifying Ang II-induced collagen synthesis $(2,4)$.

The extracellular portion of $D D R l$ is responsible for binding collagen, and when collagen is bound, its intracellular portion is activated which leads to the induction of inflammatory response and collagen synthesis, which enhances collagen binding and further increases inflammation. This positive feedback leads to the development of fibrosis (4). Unfortunately, insufficient evidence is available on the effects of $D D R 1$ 
antagonists, and no pharmacologic inhibitor for $D D R 1$ is available yet.

Several genes, such as Cosmc, megsin, IL5RA, TNFRSF6B, IL-1 cluster, TFRC, haem oxygenase-1, Fcgr $3 b$, angiotensinconverting enzyme, and endothelin-A receptor are known to be related with the development of $\operatorname{IgAN}(18-20)$. The present study suggests that the rs1264319 SNP of DDR1 confers susceptibility to $\operatorname{IgAN}$ and that it is a predictive marker of the pathological progression of IgAN. However, DDRl has not been previously reported to be a susceptibility gene in IgAN, especially in children.

As described above, DDRl appears to play a crucial role in the control of ECM and tissue fibrosis. Furthermore, rs1264319 was found to be associated with the biopsy-based progression of IgAN. These results concur with those of previous studies, in which $D D R l$ gene polymorphisms were suggested to be related with disease progression (1-4). In addition, we found that rs2267641 and rs9468843 were significantly associated with the development of proteinuria during the course of IgAN. Accordingly, we believe that $D D R 1$ may have an effect on both of the development of proteinuria and disease progression, because proteinuria and an advancement of glomerulonephritis are known to be closely related. Nevertheless, this study failed to demonstrate an association between $D D R l$ haplotype and disease frequency.

These discrepancies could be produced by the mean age difference between our cases and controls (11.82 \pm 4.87 vs. $36.40 \pm 8.32$ years, respectively) as a limitation of this study in terms of the allele frequency differences in case-control genotype and haplotype analysis.

However, we were unable to enroll age-matched controls. Because $\operatorname{IgAN}$ is known to develop in the third decade, and thus, healthy controls aged $>20$ years old were required to avoid the recruitment of individuals with undetected or subclinical IgAN. Accordingly, the presence of a substantial age gap between cases and controls appears unavoidable in studies on pediatric IgAN. Other workers have also utilized adult controls in studies on SNPs in childhood $\operatorname{IgAN}(18,19)$.

$D D R 1$ is a possible susceptibility marker of diseases other than renal diseases, such as schizophrenia, ovarian cancer, juvenile oligoarthritis, hearing loss, Churg-Strauss syndrome, small cell lung carcinoma, and endometrial cancer $(6-10,21,22)$. Notably, in one study on schizophrenia (9), in which rs1049623 was found to be a susceptibility marker, but this SNP was found to have no significance in the present study. On the other hand, rs2267641 was found to be a significant candidate SNP in the present study, but had significance only as a haplotype (rs1049623, rs2267641, and rs2239518). However, the other SNPs that showed significant associations in our study (rs1264319 and rs9468843) have not been previously reported to be single or haplotype markers.

Among the SNPs found to be significantly associated with the pathogenesis of IgAN in the present study, rs 1264319 and rs2267641 are located in the exon regions. But, they are known as synonymous SNPs and it is very difficult to explain the expected function of these SNPs in the pathogenesis of disease although recently some reports have been issued that synonymous SNPs have an important role in the protein activities and specificities without influencing amino acid sequences $(23,24)$.
Even though previous studies contradict our finding (6-10,21,22), these studies nevertheless suggested that the DDRl gene participates in the development and progression of diseases, such as, auto-inflammatory and renal diseases.

To our knowledge, DDRl related polymorphisms have not been previously examined in $\operatorname{IgAN}$. However, it is evident that DDRl is important during the development and progression of IgAN, and thus, we suggest that more DDR1 gene polymorphisms should be investigated. Also, to determine associations more reliably and to reduce age bias, a study on an older IgAN patient group is required. Furthermore, further studies are required to determine the roles of synonymous SNPs.

Summarizing, in the present study, associations were found between rs1264319 and disease susceptibility and progression. Furthermore, rs2267641 and rs9468843 were found to be associated with the development of proteinuria during the disease course.

\section{Acknowledgements}

This research was supported by the Program of Kyung Hee University for the Young Researcher of Medical Science in 2009 (KHU-20091437).

\section{References}

1. Curat CA and Vogel WF: Discoidin domain receptor 1 controls growth and adhesion of mesangial cells. J Am Soc Nephrol 13: 2648-2656, 2002.

2. Flamant M, Placier S, Rodenas A, et al: Discoidin domain receptor 1 null mice are protected against hypertension-induced renal disease. J Am Soc Nephrol 17: 3374-3381, 2006.

3. Gross O, Beirowski B, Harvey SJ, et al: DDR1-deficient mice show localized subepithelial GBM thickening with focal loss of slit diaphragms and proteinuria. Kidney Int 66: 102-111, 2004.

4. Ronco $\mathrm{P}$ and Chatziantoniou C: Matrix metalloproteinases and matrix receptors in progression and reversal of kidney disease: therapeutic perspectives. Kidney Int 74: 873-878, 2008.

5. Vogel W, Gish GD, Alves F and Pawson T: The discoidin domain receptor tyrosine kinases are activated by collagen. Mol Cell 1: 13-23, 1997.

6. Ford CE, Lau SK, Zhu CQ, Andersson T, Tsao MS and Vogel WF: Expression and mutation analysis of the discoidin domain receptors 1 and 2 in non-small cell lung carcinoma. Br J Cancer 96: 808-814, 2007.

7. Laval S, Butler R, Shelling AN, Hanby AM, Poulsom R and Ganesan TS: Isolation and characterization of an epithelialspecific receptor tyrosine kinase from an ovarian cancer cell line. Cell Growth Differ 5: 1173-1183, 1994.

8. Meyer zum Gottesberge AM, Gross O, Becker-Lendzian U, Massing $\mathrm{T}$ and Vogel WF: Inner ear defects and hearing loss in mice lacking the collagen receptor DDR1. Lab Invest 88: 27-37, 2008.

9. Roig B, Virgos C, Franco N, et al: The discoidin domain receptor 1 as a novel susceptibility gene for schizophrenia. Mol Psychiatry 12: 833-841, 2007.

10. Zeggini E, Reginato AM, Prais A, Thomson W, McLean W and Donn R: Linkage and association studies of discoidin domain receptor 1 (DDR1) single nucleotide polymorphisms (SNPs) in juvenile oligoarthritis. Rheumatology 43: 1138-1141, 2004.

11. Lee R, Eidman KE, Kren SM, Hostetter TH and Segal Y: Localization of discoidin domain receptors in rat kidney. Nephron Exp Nephrol 97: E62-E70, 2004.

12. Flynn LA, Blissett AR, Calomeni EP and Agarwal G: Inhibition of Collagen Fibrillogenesis by Cells Expressing Soluble Extracellular Domains of DDR1 and DDR2. J Mol Biol (In press).

13. Rosner B: The calculations are the customary ones based on the normal approximation to the binomial distribution. In: Fundamentals of biostatistics Mass. Duxbury, Boston, p Section $10.17,1995$. 
14. Gabriel SB, Schaffner SF, Nguyen H, et al: The structure of haplotype blocks in the human genome. Science 296: 2225-2229, 2002.

15. Yap HK, Quek CM, Shen Q, Joshi V and Chia KS: Role of urinary screening programmes in children in the prevention of chronic kidney disease. Ann Acad Med 34: 3-7, 2005

16. Cho BS, Kim SD, Choi YM and Kang HH: School urinalysis screening in Korea: prevalence of chronic renal disease. Pediatr Nephrol 16: 1126-1128, 2001.

17. Park YH, Choi JY, Chung HS, et al: Hematuria and proteinuria in a mass school urine screening test. Pediatr Nephrol 20: 1126-1130, 2005.

18. Maruyama K, Yoshida M, Nishio H, et al: Polymorphisms of renin-angiotensin system genes in childhood IgA nephropathy. Pediatr Nephrol 16: 350-355, 2001

19. Nakanishi K, Sako M, Yata N, et al: A-20C angiotensinogen gene polymorphism and proteinuria in childhood IgA nephropathy. Pediatr Nephrol 19: 144-147, 2004
20. Santos NM, Ault BH, Gharavi AG, et al: Angiotensin-converting enzyme genotype and outcome in pediatric IgA nephropathy. Pediatr Nephrol 17: 496-502, 2002.

21. Domenyuk VP, Litovkin KV, Verbitskaya TG, Dubinina VG and Bubnov VV: Identification of new DNA markers of endometrial cancer in patients from the Ukrainian population. Exp Oncol 29: 152-155, 2007.

22. Matsuyama W, Mitsuyama H, Ono M, et al: Discoidin domain receptor 1 contributes to eosinophil survival in an NF-kappaBdependent manner in Churg-Strauss syndrome. Blood 109: 22-30, 2007.

23. Komar AA: Silent SNPs: impact on gene function and phenotype. Pharmacogenomics 8: 1075-1080, 2007.

24. Kimchi-Sarfaty C, Oh JM, Kim IW, et al: A 'silent' polymorphism in the MDR1 gene changes substrate specificity. Science 315: 525-528, 2007 